\title{
Recomendaciones para el manejo de pacientes que requieren atención oftalmológica durante la pandemia de SARS-CoV-2
}

\section{Recommendations for the management of patients that require eye care during the SARS-CoV-2 pandemic}

\author{
Juan P. Olivares-de Emparan ${ }^{1}$, Manuel Garza-Leon², Gerardo García-Aguirre ${ }^{3}$, Tonath Azcárate-Coral', \\ Jason A. Penniecook ${ }^{5}$, Van Charles Lansing ${ }^{6,7}$ y Jesús Jiménez-Román ${ }^{8 *}$
}

NOTA INFORMATIVA: El presente manuscrito ha pasado un proceso de revisión excepcional interno para agilizar la difusión al ser información urgente de especial interés para la comunidad oftalmológica.

${ }^{1}$ Servicio de Segmento Anterior, Asociación para Evitar la Ceguera en México, Ciudad de México, México; ${ }^{2}$ Departamento de Ciencias Clínicas

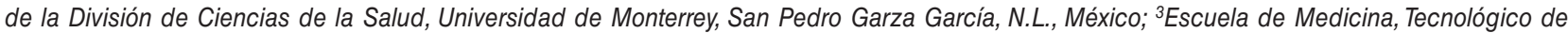
Monterrey, Monterrey, N.L., México; ${ }^{4}$ Comité Académico, Colegio de Oftalmólogos del Estado de Yucatán, Yucatán, México; ${ }^{5}$ Instituto de la Visión, Universidad de Montemorelos, Montemorelos, N.L., México; ${ }^{6}$ Instituto Mexicano de Oftalmología, Querétaro, Qro., México; ${ }^{7} \mathrm{Help}$ Me See, Nueva York, EE.UU; ${ }^{8}$ Servicio de Glaucoma, Asociación para Evitar la Ceguera en México, Ciudad de México, México

\section{Resumen ejecutivo}

La pandemia actual por el coronavirus SARS-CoV-2 ha estado fuertemente ligada a la oftalmología desde sus inicios. El 10 de enero de 2020, el New York Times anunciaba que el Dr. Li había contraído la enfermedad tras haber atendido a una paciente con glaucoma agudo. El 11 de marzo del 2020, la Organización Mundial de la Salud declaró la pandemia'. La alta tasa de transmisión del virus pone a México en un escenario en donde, según la Secretaría de Salud, se estima que el virus podría llegar a infectar al $70 \%$ de la población del país y que, tan solo en su etapa aguda, la epidemia podría durar al menos 12 semanas en nuestro país.

Método de transmisión:

- Se debe a aerosoles al estar en contacto con una persona portadora del virus o que padezca la enfermedad COVID-192-4.

- Ingreso del virus a través de las mucosas después de tocar superficies u objetos en los que se encuentre el virus presente (fómites) ${ }^{2-4}$.
- El virus tiene un periodo de incubación de 2 a 14 días, con un promedio de 5 a 7 días. El $97 \%$ de los pacientes desarrolla síntomas en 11.5 días, de ahí la importancia del aislamiento por 14 días $^{1}$.

Cuadro clínico²:

- Fiebre superior a $38{ }^{\circ} \mathrm{C}$ en el $90 \%$ de los casos.

- Tos seca hasta en el $70 \%$ de los casos.

- Ataque al estado general y cefalea.

- En el 2 a 3\% de los casos puede haber alteraciones gastrointestinales.

- Hasta el momento no existe tratamiento efectivo ni vacuna contra la enfermedad ${ }^{2}$.

Relación oftalmológica con el COVID-19:

- Presencia del virus SARS-CoV-2 en la lágrima de pacientes con COVID-191,5.

- Se ha descrito un cuadro de conjuntivitis inespecífica ${ }^{5,6}$.

- La distancia de trabajo del oftalmólogo aumenta el riesgo de transmisión.

Recomendaciones para el manejo oftalmológico ${ }^{7-11}$ : 
- Realizar categorización (triaje) de pacientes previo al ingreso a la sala de espera.

- Lavado de manos de médico y paciente previo a iniciar el interrogatorio y la exploración.

- Distancia de 2 metros entre el médico y el paciente durante el interrogatorio.

- Uso de escudo facial en la lámpara de hendidura.

- Uso de mascarilla quirúrgica tanto por parte del médico como del paciente.

- Lavado de manos o uso de gel antibacterial de médico y paciente al terminar la consulta.

- En la sala de espera evitar aglomeraciones, establecer una distancia de al menos 1 metro y medio cuando los pacientes estén sentados.

- Espaciar las citas, con el objeto de mantener una revisión fluida y cumplir las medidas de limpieza de asepsia antes y después de cada revisión.

- Utilizar solo un cubículo para la exploración.

- En caso de pacientes sospechosos, se recomienda uso de mascarilla quirúrgica de 3 capas por parte del paciente y mascarilla N95 por parte del médico, guantes de látex para la exploración, bata y gorro quirúrgico y desinfección del consultorio.

- En casos confirmados, ya sea con sintomatología leve o grave, se debe valorar la relevancia de la atención oftalmológica. Si el paciente no presenta una condición urgente o grave, podría ser evaluado posteriormente.

- Algunas sociedades internacionales de oftalmología han sugerido limitar la atención de pacientes no urgentes.

Permanencia y viabilidad del virus:

- La viabilidad del virus es de 4 horas en superficies de cobre, 8 en cartón y hasta 72 en plástico y acero inoxidable 4 .

Medidas de limpieza y desinfección:

- Lavado continuo de manos y el uso de elementos de protección son la base para mitigar la propagación del virus.

- Limpieza de pisos, paredes, superficies en el consultorio o clínica, se puede usar cloro diluido en agua. Limpieza y desinfección en oftalmología ${ }^{12-14}$ :

- Agua y jabón quirúrgico para el lavado de manos del personal.

- Alcohol en gel al 70\% para la desinfección de manos del personal.

- Solución de hipoclorito de sodio al $0.21 \%$ para la limpieza del tonómetro.

- Solución de NK-cide de $20 \mathrm{ml}$ en 1 I de agua para remojar el instrumental quirúrgico.
- Solución de amonio cuaternario para superficies de trabajo (remojar y dejar secar por 4 minutos).

Las recomendaciones recogidas en este documento deberán ser adaptadas de acuerdo con las circunstancias particulares de cada equipo de profesionales de la salud. Dichas recomendaciones variarán a medida que se genere mayor evidencia respecto al impacto de la enfermedad en la atención oftalmológica de los pacientes. Por tal motivo, el presente documento se actualizará de manera continua conforme emerjan nuevas recomendaciones con el sustento científico suficiente para modificar nuestra conducta de atención.

\section{Introducción}

La pandemia actual por el coronavirus SARS-CoV-2 está ligada a la oftalmología desde su inicio. El 30 de diciembre de 2019, el Dr. Li Wenliang, médico oftalmólogo de 34 años, observó 7 casos con un brote de neumonía intersticial similar al síndrome respiratorio agudo grave (SARS) en el Hospital Central de Wuhan. El especialista advirtió a sus colegas a través de la red social WeChat acerca del probable brote. El 10 de enero de 2020, el New York Times anunciaba que el Dr. Li había contraído la enfermedad tras haber atendido a una paciente con glaucoma agudo de ángulo cerrado, quien habría adquirido la enfermedad de su hija. Finalmente, el joven oftalmólogo falleció el 7 de febrero de $2020^{2,15}$.

El 30 de enero de 2020, un mes después de la advertencia por parte del Dr. Li, la Organización Mundial de la Salud (OMS) declaró al brote como una emergencia de salud pública de interés internacional, y el 11 de marzo fue declarada pandemia ${ }^{1}$. Al 22 de marzo había 294,110 casos reportados en 187 países o territorios ${ }^{16}$. Para acceder a los datos actualizados del número de casos a nivel global y regional se recomienda acceder a las siguientes ligas:

- Mapa situacional OMS (https://covid19.who.int)

- Mapa situacional PAHO (https://bit.ly/35lc5qE)

La alta tasa de transmisión del virus pone a México en un escenario en donde, según la Secretaría de Salud, se estima que el virus podría llegar a infectar al $70 \%$ de la población del país y que, tan solo en su etapa aguda, la epidemia podría durar al menos 12 semanas en nuestro país.

La erradicación completa de la transmisión no se vislumbra en un horizonte cercano y, debido a la situación actual de emergencia, la Sociedad Mexicana de Oftalmología y el Centro Mexicano de Salud Visual 
Preventiva invitan a la comunidad oftalmológica de México a llevar a cabo todas las acciones necesarias para afrontar, de manera eficiente, la crisis sanitaria que se vive actualmente en nuestro país, disminuyendo los riesgos para nuestros pacientes, familiares, colaboradores de trabajo y para nosotros mismos; mientras continuamos velando por la salud visual de nuestra población.

\section{Información relevante y epidemiología de la enfermedad}

El virus SARS-CoV-2 es un virus RNA con envoltura, de una sola cadena. Los coronavirus son virus de transmisión zoonótica, y la especie recientemente descubierta no había causado enfermedad previamente en humanos ${ }^{2}$.

El método de transmisión se debe a aerosoles al estar en contacto con una persona portadora del virus o que padezca la enfermedad, COVID-19; así como al ingreso del virus a través de las mucosas después de tocar superficies $u$ objetos en los que se encuentre el virus presente (fómites) ${ }^{2-4}$.

El virus tiene un periodo de incubación de 2 a 14 días, con un promedio de 5 a $7^{2}$. El $97 \%$ de los pacientes desarrolla síntomas en 11.5 días, de ahí la importancia del aislamiento por 14 días 1 . El número básico de reproducción $(R 0)$ se ha calculado en 2.2-3.02, lo cual significa que una persona contagiará de 2.2 a 3 personas durante el transcurso de su enfermedad. Para lograr el control de la infección, la $R 0$ debe disminuir de 1, por lo que el aislamiento y detección son de suma importancia.

Se han descrito tres fases epidemiológicas dependiendo del origen de los casos y el número de estos, algunas de las recomendaciones recopiladas en el presente documento hacen referencia a estas fases (Tabla 1):

Aproximadamente 4 de cada 5 personas con la enfermedad requieren solamente de aislamiento y medidas de soporte en casa. El 20\% restante podrá requerir hospitalización debido a neumonía intersticial bilateral, siendo hasta el $5 \%$ de los enfermos los que requieren ventilación mecánica.

Los factores de riesgo para los casos graves son la edad mayor de 60 años y comorbilidades, principalmente inmunodeficiencias, diabetes e hipertensión.

El cuadro clínico incluye fiebre superior a $38{ }^{\circ} \mathrm{C}$ en más del $90 \%$ de los casos, tos seca hasta en el $70 \%$ de los casos, además de ataque al estado general y cefalea. Existen cuadros atípicos con esputo en el $28 \%$
Tabla 1. Fases epidemiológicas

\begin{tabular}{|l|l|}
\hline Fase & Característica principal \\
\hline 1. Importación de casos & $\begin{array}{l}\text { Los casos detectados se originan } \\
\text { fuera del país }\end{array}$ \\
\hline $\begin{array}{l}\text { 2. Transmisión } \\
\text { comunitaria }\end{array}$ & $\begin{array}{l}\text { Contagios entre personas dentro del } \\
\text { país }\end{array}$ \\
\hline 3. Etapa epidemiológica & $\begin{array}{l}\text { Afección de miles de personas en } \\
\text { distintas regiones geográficas del } \\
\text { país }\end{array}$ \\
\hline
\end{tabular}

de los casos, y en el 2 a 3\% puede haber alteraciones gastrointestinales como vómito o diarrea ${ }^{2}$ Sociedades internacionales de otorrinolaringología ${ }^{17,18}$ han reportado anosmia, hiposmia y disgeusia como parte del cuadro clínico, ya sea asociado a otros síntomas típicos o siendo la única manifestación, o inclusive la inicial. La Sociedad Española de Oftalmología los incluye dentro de sus recomendaciones como parte de los síntomas a interrogar ${ }^{11}$.

Hasta el momento no existe tratamiento efectivo ni vacuna contra la enfermedad ${ }^{2}$. El tratamiento actual se basa en medidas generales para el manejo de los síntomas en casa y de soporte ventilatorio para los casos que requieren hospitalización. El primer ensayo clínico para el desarrollo de una vacuna se inició el 16 de marzo de 2020.

La tasa de mortalidad ha mostrado un aumento desde el inicio de la pandemia. Al 22 de marzo de 2020 era del $4.2 \%{ }^{19}$ y según la tendencia podría continuar aumentando conforme avanza la historia natural de la enfermedad. La estimación de la mortalidad con modelos estadísticos es del 5.3 a $8.4 \%$.

\section{Datos epidemiológicos en México}

El primer caso confirmado en nuestro país fue el 28 de febrero. Según fuentes oficiales, al 22 de marzo existen 316 casos confirmados y 793 sospechosos. Se han registrado casos confirmados en 31 estados $^{19}$.

Se han detectado portadores asintomáticos en el país y se sospecha que la transmisión local es ya un hecho a pesar de no haber sido corroborada por las autoridades sanitarias del país. El primer deceso se dio el 18 de marzo ${ }^{19}$. Para consultar los datos actualizados en México, acceder a:

Secretaría de Salud - Coronavirus/COVID-19. Comunicado técnico diario (https://bit.ly/2xqnIWu). 


\section{Importancia en oftalmología}

Desde el punto de vista oftalmológico se ha descrito la presencia del virus SARS-CoV-2 en la lágrima de pacientes con COVID-196,20,21. También se ha descrito un cuadro de conjuntivitis inespecífica en el 0.8 a $1 \%$ de los casos, considerado uno de los escenarios de presentación de la enfermedad ${ }^{1,22}$.

Existen numerosos reportes acerca del riesgo de transmisión al personal de salud, inclusive por pacientes asintomáticos ${ }^{1,3,22}$. Hasta este momento no se ha determinado el riesgo específico de contraer la enfermedad por parte de oftalmólogos, sin embargo, la distancia de trabajo durante la exploración de los pacientes en la lámpara de hendidura y durante los procedimientos oftalmológicos podría aumentar el riesgo $0^{1,6}$.

Se ha demostrado la infección intraocular con algunas cepas de coronavirus murinos en ratones, que causaron inflamación y degeneración de la retina (retinopatía experimental por coronavirus) ${ }^{21}$.

Es probable que la epidemia actual nos ayude a entender mejor la capacidad de daño del SARS-CoV-2 a los tejidos oculares, mientras tanto debemos estar alerta a la evidencia que surja.

\section{Medidas de prevención y protección en el consultorio y el hospital}

Se ha demostrado que la distancia a la que viajan las partículas emitidas al hablar, estornudar o toser dependerá del evento del que se trate, además de las condiciones ambientales. En un estudio controlado, Xie, et al. determinaron que las partículas exhaladas pueden viajar a 1 metro tan solo al hablar y respirar, 2 metros en el caso de toser y 6 metros al estornudar ${ }^{23,24}$.

La permanencia y viabilidad del virus en distintas superficies fue reportada en el New England Journal of Medicine. En el estudio realizado se reportó la viabilidad del virus durante 4 horas en superficies de cobre, 8 en cartón y hasta 72 en plástico y acero inoxidable 4 .

Por lo que las medidas de limpieza y desinfección, junto con el lavado de manos y el uso de elementos de protección, son la base para mitigar la propagación del virus.

Es importante la separación del área de trabajo del médico y el área de exploración (no mezclar insumos entre áreas).

\section{Limpieza y desinfección}

Para la limpieza de pisos, paredes y superficies en el consultorio o clínica se puede usar cloro diluido en agua. Los centros de control de enfermedad de Estados Unidos (CDC) recomiendan 25 :

- 4 cucharadas pequeñas $(20 \mathrm{ml})$ en 1 I de agua 0

- 5 cucharadas grandes ( $75 \mathrm{ml}$ ) en 1 galón (3.8 I)

Para la limpieza y desinfección se pueden usar las siguientes soluciones en oftalmología ${ }^{12-14}$ :

- Agua y jabón quirúrgico para el lavado de manos del personal.

- Alcohol en gel al 70\% para la desinfección de manos del personal.

- Solución de hipoclorito de sodio al $0.21 \%$ para la limpieza del tonómetro.

- Solución de NK-cide de $20 \mathrm{ml}$ en 1 I de agua para remojar instrumental quirúrgico que vaya a ser usado en el consultorio.

- Solución de amonio cuaternario para superficies de trabajo (remojar y dejar secar por 4 minutos).

\section{Lavado de manos y uso de elementos de protección}

Debido al riesgo de transmisión, y ya que la distancia de exploración de nuestra especialidad es menor a 1 metro se recomienda:

\section{Para PACIENTES SIN ANTECEDENTE dE EXPOSICIÓN (NIVEL DE PROTECCIÓN BÁSICO) $)^{9,11}$}

- Durante el interrogatorio:

- Lavado de manos previo a iniciar el interrogatorio y el uso del teclado.

- Distancia mayor a 2 metros entre el médico y el paciente.

- Durante la exploración:

- Uso de escudo facial en la lámpara de hendidura y mascarilla quirúrgica tanto el médico como el paciente; uso de una capa de guantes de nitrilo para tocar al paciente, en caso de que ser necesario.

- Si se llevan insumos a la mesa de la lámpara de hendidura, deben quedarse ahí hasta que sean desinfectados.

- Desinfectar el consultorio después de usarse por cada paciente.

- Lavado de manos por parte del médico al terminar la consulta.

\section{Para pacientes SOSPECHOSOS}

(NIVEL DE PROTECCIÓN INTERMEDIO)

La Sociedad Española de Oftalmología recomienda solamente atender a pacientes con urgencias 
oftalmológicas en ausencia de síntomas de la enfermedad $^{11}$. En caso de ser necesario, las medidas de protección son s,26: $^{9}$

- Durante el interrogatorio:

- Lavado de manos previo a iniciar el interrogatorio y el uso del teclado.

- Distancia mayor a 2 metros entre el médico y el paciente.

- Uso de mascarilla quirúrgica de 3 capas por parte del paciente y mascarilla N95 por parte del médico.

- Durante la exploración:

- Uso de escudo facial en la lámpara de hendidura y escudo facial industrial si la exploración es fuera de la lámpara de hendidura.

- Uso de gorro quirúrgico desechable.

- Uso de guantes de látex (de nitrilo en caso de haber alergia por parte del médico o del paciente).

- Uso de mascarilla quirúrgica por parte del paciente y de mascarilla N95 por parte del médico, así como de gafas protectoras que sellen sobre la piel del médico.

- Uso de bata desechable quirúrgica por parte del médico.

- Si se llevan insumos a la mesa de la lámpara de hendidura, deben quedarse ahí hasta que sean desinfectados.

- Desinfectar el consultorio después de usarse por cada paciente.

- Lavado de manos por parte del médico al terminar la consulta.

\section{Para pacientes con prueba confirmada positiva PARA SARS-COV-2}

Deberán ser referidos a un hospital adecuado para el manejo de los casos. No se recomienda la atención oftalmológica hasta que un médico de urgencias o personal capacitado para el manejo de estos pacientes haya evaluado el caso desde el punto de vista sistémico ${ }^{11}$.

Para los médicos oftalmólogos que atiendan a estos pacientes en los hospitales de referencia, se recomienda ${ }^{11,26}$ :

- Realizar la atención en un consultorio designado específicamente para ello.

- Contar con toda la protección recomendada o la disponible según el centro.

- Tener especial cuidado al estar en contacto con la conjuntiva de los pacientes.

- Desechar todos los insumos y los frascos de gotas multidosis que se hayan utilizado durante la consulta.
Para más información respecto a la protección del personal de salud se recomienda revisar el Manual para la Prevención y Tratamiento de COVID-19 del First Affiliated Hospital, Zhejiang University School of Medicine, el cual estará disponible en español en los próximos días.

Handbook of COVID-19 Prevention and Treatment.

\section{Recomendaciones específicas para la atención de pacientes oftalmológicos}

La recomendación inicial es realizar una categorización epidemiológica (triaje) a los pacientes que soliciten atención oftalmológica, para este propósito se debe interrogar ${ }^{10,11}$ :

- Presencia de síntomas: fiebre, tos, malestar general, cefalea, diarrea y alteraciones gastrointestinales, anosmia y disgeusia.

- Antecedente de viaje fuera de México en los últimos 14 días (fase 1 de la epidemia).

- Antecedente de convivencia o contacto con alguna persona con sospecha o caso confirmado de COVID-19 (fases 2 y 3 de la epidemia).

Además de la categorización epidemiológica (triaje) es necesario investigar la causa de solicitud de la atención oftalmológica. Algunas sociedades internacionales de oftalmología recomiendan solo atender casos urgentes $7,8,11,27$. Se propone considerar esta recomendación para limitar los contactos potencialmente contagiosos. La decisión final dependerá del sentido común y evaluación clínica, así como la fase epidemiológica en que nos encontremos.

Una vez que hemos decidido que es necesario atender a nuestro paciente, debemos mantener la idea que nuestro primer objetivo es evitar la exposición del paciente y el personal de salud a un paciente infectado, para esto, debemos seguir los lineamientos básicos de salud pública, que incluyen no tener aglomeración de personas en nuestras instalaciones, por lo que se debe: - Solicitar que acudan con un solo acompañante.

- De ser posible, espaciar los horarios de consulta para que no coincidan dos pacientes en la sala de espera.

- Mantener la cuarentena de pacientes con síntomas de la enfermedad o diagnóstico confirmado, por lo que previo a la entrada del paciente al consultorio se sugiere la toma de la temperatura y, en caso de ser igual o superior a $38^{\circ} \mathrm{C}$, derivar al paciente al hospital adecuado.

Dentro de los cuidados generales que debemos utilizar se encuentran la colocación de un escudo protector en la lámpara de hendidura (Fig. 1), el uso de mascarillas 


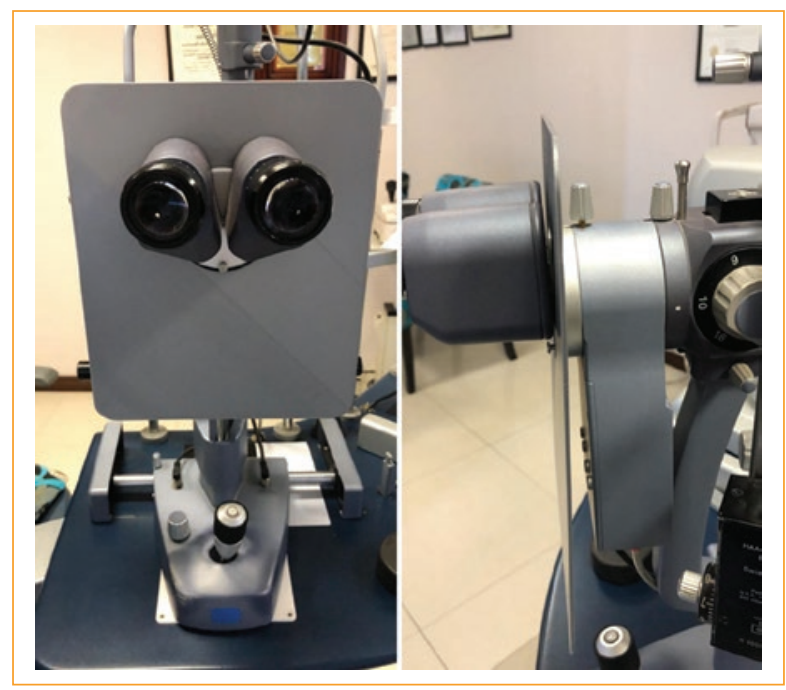

Figura 1. Colocación y uso de escudo protector en la lámpara de hendidura (cortesía del Dr. Manuel Garza León).

quirúrgicas o N-95 según el riesgo con cada paciente (sección 4) y el aseo de las manos con agua y jabón o alcohol al $70 \%$ entre cada paciente, además de una limpieza de las superficies que estuvieron en contacto con el paciente con hipoclorito de sodio al $10 \circ 20 \% \%^{9,14}$.

La evaluación de pacientes con diagnóstico sugestivo o confirmado de COVID-19 debe realizarse en hospitales que tengan los recursos necesarios. Además de las precauciones ya mencionadas, se debe agregar el uso de guantes, lentes protectores y ropa adecuada. Estos equipos deben eliminarse en una bolsa de manejo de residuos peligrosos al finalizar la evaluación (sección 4).

Uno de los procedimientos rutinarios en la exploración oftalmológica es la toma de la presión intraocular (PIO); sin embargo, es importante recordar que estudios de otros coronavirus sugieren que la infección se podría trasmitir a través de la lágrima ${ }^{21}$, por lo que se debe decidir si es necesario tomar la PIO. Si es indispensable tomarla, se sugiere que se realice con métodos de contacto y no a través de tonómetros de aire, ya que la aplicación de una fuerza de aire intensa puede producir la aerosolización de las gotas de lágrima al ambiente. Idealmente, la superficie de contacto debe ser desechable, por lo que el uso del Tonopen o el iCare podrían ser la mejor opción; sin embargo, por la accesibilidad, el tonómetro de Goldmann, siendo el método más utilizado, si se cuenta con puntas desechables, se deben de utilizar, y en caso de no contar con ellas, la desinfección con hipoclorito de sodio al $10 \%$ o, en segundo lugar, el alcohol al $70 \%$ son métodos adecuados ${ }^{12}$.
La tabla 2 muestra de manera práctica las situaciones más comunes a las que nos enfrentaremos como oftalmólogos en nuestra práctica diaria. Las recomendaciones se generaron con el conocimiento actual. Esto podría cambiar rápidamente, y se sugiere mantenerse informado de las últimas actualizaciones.

\section{Situaciones especiales}

\section{Pacientes bajo tratamiento InMUNOMOdULAdoR}

Como parte del tratamiento de diversas enfermedades inflamatorias, algunos pacientes oftalmológicos pueden estar utilizando agentes inmunomoduladores tanto biológicos (adalimumab, infliximab, rituximab, entre otros) como clásicos (metotrexato, azatioprina, ciclosporina, etc.). Debido a que hasta el momento no se cuenta con información científica que sugiera un mayor riesgo de padecer COVID-19 o que la evolución sea peor a la de pacientes que no los utilizan, además del riesgo para la visión por suspender el medicamento, la Liga Europea contra el Reumatismo (EULAR) ha sugerido que se mantenga el tratamiento con la dosis y frecuencia indicada por su médico ${ }^{28,29}$.

En caso de que el paciente presente fiebre o tos persistente, deberá seguir los consejos nacionales para acceder a la atención médica, llamando por teléfono a las líneas de ayuda. Si el paciente es positivo para COVID-19, deberá discutirse con su médico tratante las ventajas y desventajas de la suspensión del tratamiento. Mientras tanto, si aún no lo ha hecho, sería prudente completar la protección de la vacunación de acuerdo con las recomendaciones EULAR y las pautas nacionales, actualmente con prioridad contra la influenza, la tos ferina y el neumococo ${ }^{28}$.

Es interesante conocer que debido a que parte del daño tisular asociado al COVID-19 es secundario a la respuesta inmune por la presencia del SARS-CoV-2 en el cuerpo, recientemente se ha iniciado un estudio aleatorizado, doble enmascarado para evaluar el efecto del uso de tocilizumab (anticuerpo monoclonal humanizado dirigido contra el receptor de la IL-6, aprobado para el tratamiento de la artritis reumatoide) como tratamiento coadyuvante para pacientes con neumonía severa por COVID-1930.

\section{Pacientes en lista de espera para trasplante de CÓRNEA}

Hasta el momento se desconoce el riesgo de contaminación corneal de un paciente fallecido por COVID-19, 
Tabla 2. Situaciones más comunes a las que nos enfrentaremos como oftalmólogos en nuestra práctica diaria

\begin{tabular}{|c|c|}
\hline Situación & Recomendaciones \\
\hline $\begin{array}{l}\text { Pacientes de seguimiento que no tengan } \\
\text { urgencias oftalmológicas, sin síntomas } \\
\text { respiratorios }\end{array}$ & $\begin{array}{l}\text { - Atención vía telefónica o aplicaciones digitales* (whatsapp, skype) } \\
\text { - Recomendar esperar a que pase la crisis sanitaria para acudir a atención } \\
\text { - Indicar comunicarse en caso de que su situación respecto a la visión cambie }\end{array}$ \\
\hline $\begin{array}{l}\text { Seguimiento de pacientes por enfermedades que } \\
\text { requieren seguimiento en el consultorio debido a } \\
\text { riesgo de pérdida de visión o urgencias } \\
\text { oftalmológicas; en un paciente sano, sin sospecha } \\
\text { clínica (fiebre, tos, síntomas respiratorios) ni } \\
\text { factores de riesgo para COVID-19 }\end{array}$ & $\begin{array}{l}\text { - Precauciones de limpieza y desinfección de rutina } \\
\text { - Escudo protector en la lámpara de hendidura } \\
\text { - Uso de mascarillas quirúrgicas por parte del médico y del paciente, y guantes } \\
\text { - En la medida de lo posible planear la disminución de las visitas de seguimiento y } \\
\text { valorar continuar la atención vía telefónica o por aplicaciones digitales }\end{array}$ \\
\hline $\begin{array}{l}\text { Seguimiento de pacientes (enfermedades que } \\
\text { requieren seguimiento en el consultorio por } \\
\text { riesgo de pérdida de visión) o urgencias } \\
\text { oftalmológicas con síntomas respiratorios, pero } \\
\text { sin fiebre ni factores de riesgo para COVID-19 }\end{array}$ & $\begin{array}{l}\text { - Atención en el consultorio } \\
\text { - Uso inmediato de mascarilla quirúrgica por parte del paciente cuando llega a } \\
\text { nuestro consultorio } \\
\text { - Escudo protector en la lámpara de hendidura } \\
\text { - Uso de protección por parte de médicos, enfermeras y optometristas (guantes, } \\
\text { gafas de protección, mascarillas quirúrgicas N-95) } \\
\text { - Desinfección de todo el consultorio tras la atención }\end{array}$ \\
\hline $\begin{array}{l}\text { Pacientes con síntomas respiratorios con fiebre } \\
\text { con o sin factores de riesgo para COVID- } 19\end{array}$ & $\begin{array}{l}\text { - Deben ser referidos a un hospital en donde pueda ser atendido como caso } \\
\text { sospechoso de COVID-19 } \\
\text { - Se recomienda brindar la atención oftalmológica en esas instituciones }\end{array}$ \\
\hline Pacientes confirmados con COVID-19 & $\begin{array}{l}\text { - La atención oftalmológica dependerá del estado de gravedad del paciente y el } \\
\text { riesgo de contagio para otras personas } \\
\text { - Se sugiere la atención solamente en centros designados para el manejo de } \\
\text { pacientes con la enfermedad } \\
\text { - Absolutamente necesario seguir el protocolo de seguridad (ver sección 4). } \\
\text { La protección facial completa del personal de salud es de suma importancia }\end{array}$ \\
\hline
\end{tabular}

*Aún está pendiente la recomendación legal respecto a la responsabilidad de brindar atención vía telefónica o por aplicaciones, tomando en consideración la crisis sanitaria.

†Los factores de riesgo y la definición epidemiológica de la enfermedad se actualizan continuamente, se recomienda verificar la actualización de esta en la siguiente liga: Secretaría de Salud - Aviso Epidemiológico COVID-19

además de no ser parte actual de los lineamientos de estudios séricos de cribado de pacientes donadores, sin embargo, la Asociación Americana de Bancos de Ojos ha impuesto requisitos de triaje para minimizar el riesgo de procurar córneas de pacientes con COVID-1931. En México, el Centro Nacional de Trasplantes (CENATRA) recomienda descartar la donación de órganos en los siguientes casos: casos sospechosos o confirmados de COVID-19 hasta un periodo de tiempo de al menos 21 días desde la resolución de los síntomas o pacientes SIN datos clínicos compatibles, pero con resultado positivo en las pruebas de tamizaje ${ }^{32}$.

El 17 de marzo, el CENATRA emitió recomendaciones al subsistema nacional de donación y trasplantes sobre la infección asociada al SARS-CoV-2 (COVID19), el más importante es la SUSPENSIÓN TEMPORAL de todos los programas de donación y trasplante de órganos y tejidos a nivel nacional hasta nuevo aviso, con excepción de los trasplantes de tejido corneal ya programados para la semana del 17 al 22 de marzo de 2020 en los que ya se cuente con el tejido disponible en banco o en el establecimiento.
En caso de que sea indispensable realizar un trasplante durante la suspensión temporal de la actividad, deberán ser notificados al CENATRA por la vía correspondiente. Además, se recomienda la inclusión de pruebas de tamizaje para COVID-19 como parte de los estudios pretrasplante en los casos de urgencia nacional, asignación prioritaria y los trasplantes de córnea programados para la semana del 17 al 22 de marzo de $2020^{32}$.

\section{Adaptación y uso de LENTES dE CONTACTO}

Hasta el momento no existe evidencia para recomendar suspender el uso de lentes de contacto a pacientes sanos. Tampoco existe evidencia que el uso de lentes de contacto favorezca la propagación del SARS-CoV- ${ }^{11}$.

Debido a que existen casos reportados de infección vía conjuntival, es de suma importancia que los usuarios de lentes de contacto realicen el aseo de manos antes y después de colocar y quitar los lentes en el ojo. Además, durante la crisis sanitaria se puede favorecer el uso de lentes de contacto de reemplazo diario. 
La Sociedad Española de Contactología recomienda que, durante la crisis sanitaria, la desinfección de lentes de contacto que no sean de reemplazo diario, sean del material que sean, se lleve a cabo con peróxido de hidrógeno al $3 \%$, sustituyendo el uso de soluciones multipropósito ${ }^{11}$. Se sugiere considerar dicha recomendación para nuestros pacientes; al mismo tiempo no diseminar la información a la población general, debido a que la desinfección con peróxido de hidrógeno requiere de la capacitación previa de los usuarios, por riesgo de daño a la superficie ocular en caso de manejo inadecuado de las soluciones de desinfección.

No se recomienda la adaptación de lentes de contacto, hasta la resolución del cuadro clínico, en los siguientes casos:

- Pacientes con hiperemia conjuntival o síntomas de conjuntivitis.

- Pacientes con sospecha o confirmados con COVID-19.

En los pacientes con diagnóstico confirmado de COVID-19, se recomienda:

- Suspender el uso de lentes de contacto.

- Si el paciente es dependiente completamente del lente de contacto, podrá seguir usándolas con extrema higiene, utilizando para tal propósito soluciones de peróxido de hidrógeno al $3 \%^{11}$.

\section{Cirugías urgentes}

Múltiples instituciones internacionales, entre las que destacan la American Academy of Ophthalmology ${ }^{10}$, la American Society of Retina Specialists ${ }^{8}$, el American College of Surgeons ${ }^{27}$ y otras ${ }^{7}$, han acordado diferir los procedimientos quirúrgicos electivos para disminuir el riesgo de exposición a los pacientes y personal de la salud al SARS-CoV-2.

En el campo de la oftalmología se recomienda dividir las indicaciones de procedimientos quirúrgicos en tres grupos:

1) Urgentes: aquellas que de no realizarse cirugía de forma inmediata tienen un alto riesgo de causar pérdida grave e irreversible de la visión.

2)Prioritarias: aquellas que de no realizarse cirugía conllevan cierto riesgo de pérdida visual a corto plazo, pero que pueden diferirse por cierto tiempo.

3)Electivas: aquellas que de no realizarse cirugía no llevan riesgo de pérdida visual a corto plazo.

A continuación, se incluye una lista con ejemplos de los distintos procedimientos incluidos en cada grupo. La lista no pretende ser exhaustiva; cabe mencionar que el cirujano/a es quien tendrá la última palabra sobre la indicación quirúrgica respecto a un paciente en particular:

\section{Cirugías urgentes (máxima prioridad)}

- Endoftalmitis aguda que requiera vitrectomía.

- Desprendimiento de retina agudo con mácula aplicada.

- Desprendimiento de retina agudo con involucro macular reciente ( $\leq 5$ días).

- Restos cristalinianos remanentes que causen inflamación o hipertensión ocular que no se pueda controlar con medicamentos.

- Trauma ocular abierto con o sin cuerpo extraño intraocular.

- Perforación ocular que requiera recubrimiento conjuntival/parche escleral.

- Hemorragia vítrea densa en paciente monocular.

- Implante (banda, válvula) expuesto y/o infectado.

- Cualquier elevación de presión intraocular aguda $\geq$ $40 \mathrm{mmHg}$ que no pueda ser manejada con medicamentos (p.ej., glaucoma facomórfico, glaucoma neovascular, ataque agudo de glaucoma).

- Hemorragia supracoroidea aposicional.

- Hemorragia retrobulbar.

- Retinopatía del prematuro que requiera láser, vitrectomía, cerclaje, antiangiogénicos intravítreos.

- Biopsia de vítreo por sospecha de linfoma.

\section{Cirugías prioritarias (pueden diferirse por algún tiempo)}

- Desprendimiento de retina agudo con involucro macular $>5$ días.

- Restos cristalinianos remanentes con inflamación y/o presión intraocular controlados médicamente.

- Hemorragia vítrea con evidencia ecográfica de desgarro de retina.

- Cirugías de glaucoma con PIO $\leq 40 \mathrm{mmHg}$.

- Trauma palpebral con o sin involucro de la vía lagrimal.

- Casos especiales de cirugía de catarata:

- Catarata que impide la fotocoagulación en un paciente con retinopatía diabética proliferativa.

- Catarata congénita por riesgo de ambliopía.

- Trauma ocular cerrado con pérdida de la integridad de la cápsula del cristalino.

\section{Cirugías electivas (suspenderse hasta pasada la contingencia)}

- Extracción de catarata de rutina (siempre y cuando tenga la oportunidad de realizarse en otro momento).

- Excisión de pterigión.

- Cualquier cirugía refractiva.

- Cualquier cirugía cosmética. 
- Cirugía de estrabismo.

- Queratoplastia penetrante/no penetrante por indicación óptica.

- Agujero macular.

- Membrana epirretiniana.

- Tracción vitreomacular.

Además de la indicación oftalmológica respecto a la urgencia del procedimiento, debemos considerar la situación particular de cada caso. Se propone considerar esta recomendación para limitar los contactos potencialmente contagiosos; sin embargo, la decisión final dependerá del sentido común y la evaluación clínica, así como la fase epidemiológica en que nos encontremos.

\section{Inyecciones intravítreas y estudios asociados}

La población que usualmente requiere inyecciones intravítreas es la población de mayor riesgo en padecer las consecuencias graves del COVID-19 (mayores de 60 años, con diabetes, hipertensión, problemas respiratorios), por lo que deben encaminarse los esfuerzos para evitar que estos pacientes acudan al consultorio, a menos que el procedimiento se considere urgente. La relativa urgencia de realizar una inyección intravítrea dependerá principalmente del diagnóstico, tal como se describe a continuación:

- Endoftalmitis aguda: todo paciente con sospecha de endoftalmitis aguda deberá recibir inyección intravítrea de antibiótico de la misma forma y con la misma urgencia que lo haría en un periodo sin contingencia.

- Degeneración macular relacionada a la edad en fase húmeda (DMREh)/neovascularización coroidea: dado que está ampliamente demostrado que los ojos con DMREh que no reciben inyecciones a sus intervalos regulares presentan baja visual que muchas veces no es reversible ${ }^{33}$, estos pacientes deben continuar recibiendo sus inyecciones de acuerdo con el esquema que se requiera.

- Glaucoma neovascular de ángulo abierto: los pacientes que tengan neovasos en el ángulo e hipertensión ocular SIN cierre angular pueden resultar beneficiados de recibir inyecciones intravítreas ${ }^{34}$ con la finalidad de inducir regresión de los neovasos y ya sea mejorar el control de la presión intraocular o reducir el sangrado asociado a cirugía filtrante. NO está indicado diferir las inyecciones en estos casos.

- Edema macular diabético/edema macular por oclusiones venosas: A diferencia de los ojos con DMREh, en los ojos con edema macular diabético o por oclusión venosa de retina, el aplazamiento de la inyección generalmente no pone en peligro el pronóstico visual, y puede compensarse reanudando las inyecciones.

\section{Bibliografía}

1. Khanna RC, Honavar SG. All eyes on Coronavirus-What do we need to know as ophthalmologists. Indian J Ophthalmol. 2020;68:549-53.

2. Wu D, Wu T, Liu Q, Yang Z. The SARS-CoV-2 outbreak: what we know. Int J Infec Dis. 2020;pii: S1201-9712(20)30123-5.

3. Lai T, Tang E, Chau S, Fung K, Li, K. Stepping up infection control measures in ophthalmology during the novel coronavirus outbreak: an experience from Hong Kong. Graefes Arch Clin Exp Ophthalmol. 2020; doi:10.1007/s00417-020-04641-8.

4. van Doremalen N, Bushmaker T, Morris DH, Holbrook MG, Gamble A, Williamson BN, Tamin A, et al. Aerosol and surface stability of SARSCoV-2 as compared with SARS-CoV-1. N Engl J Med. 2020; doi:10.1056/ NEJMc2004973.0-2.

5. Seah I, Su X, Lingam G. Revisiting the dangers of the coronavirus in the ophthalmology practice. Eye. 2020;doi:10.1038/s41433-020-0790-7.

6. Li JO., Lam DSC, Chen Y, DSW. Novel Coronavirus disease 2019 (COVID-19): The importance of recognising possible early ocular manifestation and using protective eyewear. Br J Ophthalmol. 2010;104(3):297-8.

7. American Retina Forum. American Retina Forum Coronavirus Response. 2020. Disponible en: https://www.americanretinaforum.com/coronavirus-response.

8. American Society of Retina Specialists. COVID-19: Member Update American Society of Retina Specialists (ASRS) Member Alert Regarding the COVID-19 Pandemic. 2020. Disponible en; https://www.asrs.org/practice/ asrs-member-alert-regarding-covid-19-pandemic.

9. American Academy of Ophthalmology. Alert : Important coronavirus updates for ophthalmologists. 2020. Disponible en: https://www.aao.org/ headline/alert-important-coronavirus-context.

10. American Academy of Ophthalmology. New recommendations for urgent and nonurgent patient care. 2020. Disponible en: https://www.aao.org/ headline/new-recommendations-urgent-nonurgent-patient-care.

11. Sociedad Española de Oftalmología. Recomendaciones para la atención a pacientes oftalmológicos en relación con emergencia COVID-19. 2020. Disponible en: https://www.oftalmoseo.com/documentacion/comunicado_conjunto_oftalmologia_covid19.pdf.

12. Junk AK, Chen PP, Lin SC, Nouri-Mahdavi K, Radhakrishnan S, Singh K, et al. Disinfection of Tonometers: A Report by the American Academy of Ophthalmology. Ophthalmology, 2017;124:1867-75.

13. Kampf G, Todt D, Pfaender S, Steinmann E. Persistence of coronaviruses on inanimate surfaces and their inactivation with biocidal agents. J Hosp Infect. 2020;104:246-51.

14. United States Environmental Protection Agency. Disinfectants for Use Against SARS-CoV-2. 3-5. 2020.Disponible en: https://www.epa.gov/ pesticide-registration/list-n-disinfectants-use-against-sars-cov-2.

15. Parrish RK $2^{\text {nd }}$, Stewart MW, Duncan Powers SL. Ophthalmologists Are More Than Eye Doctors-In Memoriam Li Wenliang. Am J Ophthalmol. 2020;pii: S0002-9394(20)30067-2.

16. WHO. Coronavirus disease (COVID-19) outbreak. Emergencies - Diseases 2020. 2020. Disponible en: https://www.who.int/emergencies/diseases/novel-coronavirus-2019.

17. ENTUK. Loss of sense of smell as marker of COVID-19 infection. 2020. Disponible en: https://www.entuk.org/loss-sense-smell-marker-covid-19-infection.

18. American Academy of Otolaryngology - Head and Neck Surgery. AAOHNS : Anosmia, hyposmia and dysgeusia symptoms of coronavirus disease. 2020. Disponible en: https://entnet.org/content/coronavirus-disease-2019-resources.

19. Secretaria de Salud México. Comunicado Técnico Diario Nuevo Coronavirus en el Mundo (COVID-19) 20 marzo 2020. 2020. Disponible en: hhttps://www.gob.mx/salud/documentos/coronavirus-covid-19-comunicado-tecnico-diario-238449?idiom=es.

20. Peng, Y. \& Zhou, Y.-H. Is novel coronavirus disease (COVID-19) transmitted through conjunctiva? J Med Virol. 2020. doi:10.1002jmv.25753.

21. Seah I, Agrawal R. Can the Coronavirus Disease 2019 (COVID-19) Affect the Eyes? A Review of Coronaviruses and Ocular Implications in Humans and Animals. Ocul Immunol Inflamm. 2020; doi: 10.1080/09273948.

22. Chang D, Xu H, Rebaza A, Sharma L, de la Cruz CS. Protecting health-care workers from subclinical coronavirus infection. Lancet Respir Med. 2020;8:e13.

23. Xie X, Li Y, Chwang ATY, Ho PL, Seto WH. How far droplets can move in indoor environments - revisiting the Wells evaporation-falling curve. Indoor Air. 2007;17:211-25. 
Rev Mex Oftalmol. 2020;94(3)

24. Chen SC, Chio CP, Jou LJ, Liao CM. Viral kinetics and exhaled droplet size affect indoor transmission dynamics of influenza infection. Indoor Air 2009;19:401-13.

25. Centrer for Disease Control. How to Protect Yourself Know How it Spreads. 2019. Disponible en: https://www.cdc.gov/coronavirus/2019-ncov/prepare/ prevention.html.

26. The First Affiliated Hospital. Zhejiang University School of Medicine. Handbook of COVID-19 Prevention and Treatment. 2020.

27. American College of Surgeons. COVID-19: Guidance for Triage of Non-Emergent Surgical Procedures. (2020). Disponbile en: https://www. facs.org/covid-19/clinical-guidance/triage.

28. European league against rheumatism. EULAR Guidance for patients COVID-19 outbreak. 2020. Disponible en: https://www.eular.org/eular guidance for patients covid19 outbreak.cfm.

29. D'Antiga L. Coronaviruses and immunosuppressed patients. The facts during the third epidemic. Liver transplantation : official publication of the American Association for the Study of Liver Diseases and the International Liver Transpl. 2020. doi:10.1002/It.25756.
30. Clinical Trials Arena. Roche to start Phase III trial of Actemra in Covid-19 patients. Disponible en: https://www.clinicaltrialsarena.com/news/ roche-actemra-covid-19-trial/.

31. Eye Bank Association of America. Coronavirus Disease 2019 (COVID-19) and Eye Tissue Donation Epidemiological Risk. 2020.

32. Centro Nacional de Transplantes (CENATRA). Recomendaciones al subsistema nacional de donación y trasplantes sobre la infección asociada al SARS-CoV-2 (COVID-19). Disponible en: https://www.gob.mx/cms/ uploads/attachment/ile/541834/Recomendaciones_COVID-19.pdf.

33. Comparison of Age-related Macular Degeneration Treatments Trials CATT) Research Group. Five-Year Outcomes with Anti-Vascular Endothelial Growth Factor Treatment of Neovascular Age-Related Macular Degeneration: The Comparison of Age-Related Macular Degene. Ophthalmology. 2016;123:1751-61.

34. Wakabayashi T, Oshima Y, Sakaguchi H. Intravitreal bevacizumab to treat iris neovascularization and neovascular glaucoma secondary to ischemic retinal diseases in 41 consecutive cases. Ophthalmology. 2008;115:1571-80. 